\title{
BASIC SCIENCE ARTICLE Does prolonged severe hypercapnia interfere with normal cerebrovascular function in piglets?
}

\author{
Massroor Pourcyrous ${ }^{1,2,3}$, Sandeep Chilakala ${ }^{1}$, Mohamad T. Elabiad ${ }^{1}$, Helena Parfenova ${ }^{2}$ and Charles W. Leffler ${ }^{1,2}$
}

BACKGROUND: Hypercapnia causes cerebral vasodilation and increased cerebral blood flow (CBF). During prolonged hypercapnia it is unknown whether cerebral vasodilation persists and whether cerebrovascular function is preserved. We investigated the effects of prolonged severe hypercapnia on pial arteriolar diameters (PAD) and cerebrovascular reactivity to vasodilators and vasoconstrictors.

METHODS: Piglets were anesthetized, intubated and ventilated. Closed cranial windows were implanted to measure PAD. Changes in PAD were documented during hypercapnia $\left(\mathrm{PaCO}_{2} 75-80 \mathrm{~mm} \mathrm{Hg}\right)$. Cerebrovascular reactivity was documented during normocapnia and at 30,60 , and 120 min of hypercapnia.

RESULTS: Cerebral vasodilation to hypercapnia was sustained over $120 \mathrm{~min}$. Cerebrovascular responses to vasodilators and vasoconstrictors were preserved during hypercapnia. During hypercapnia, vasodilatory responses to second vasodilators were similar to normocapnia, while exposure to vasoconstrictors caused significant vasoconstriction.

CONCLUSIONS: Prolonged severe hypercapnia causes sustained vasodilation of pial arteriolar diameters indicative of hyperperfusion. During hypercapnia, cerebral vascular responses to vasodilators and vasoconstrictors were preserved, suggesting that cerebral vascular function remained intact. Of note, cerebral vessels during hypercapnia were capable of further dilation when exposed to additional cerebral vasodilators and, significant vasoconstriction when exposed to vasoconstrictors. Extrapolating these findings to infants, we suggest that severe hypercapnia should be avoided, because it could cause/increase cerebrovascular injury.

Pediatric Research (2018) 84:290-295; https://doi.org/10.1038/s41390-018-0061-5

\section{INTRODUCTION}

Neonates with respiratory conditions requiring initiation of mechanical respiratory support or those who are already on ventilator support may experience relatively prolonged and severe hypercapnia. While this condition can be remedied once the clinicians become aware of hypercapnia, episodes of hypercapnia may have already caused detrimental effects on cerebrovascular function.

Carbon dioxide $\left(\mathrm{CO}_{2}\right)$ is a potent cerebral vasodilator and an important regulator of cerebral blood flow (CBF). $\mathrm{PaCO}_{2}$ increases $\mathrm{CBF}$ by decreasing cerebrovascular resistance thereby dilating pial arterioles. In preterm infants $\mathrm{PaCO}_{2}$ has greater effects on $\mathrm{CBF}$ autoregulation when compared with the systemic blood pressure (BP), because the auto-regulatory zone is narrowed under the influence of high $\mathrm{PaCO}_{2}$ in this population. ${ }^{1,2}$ Hypercapnia causes increased $C B F$, while hypocapnia results in decreased $C B F . \mathrm{PaCO}_{2}$ values that exceed the physiologic range have been correlated with brain injury and neurological deficits in premature infants., Preterm infants are not only at greater risk of episodic hypercapnia, but they are also likely to be exposed to vasoactive agents and routine clinical intervention that could cause cerebral hyperemia followed by intraventricular hemorrhage (IVH). Also, infants at any gestational age might need vasopressor support in the presence of hypercapnia; it is not clear how the cerebral vessels respond in that situation.

We chose newborn piglets as a model of human infants, because of their similarity in cerebrovascular structure and function. ${ }^{5,6}$ The maturity of piglets' brain during the first week of life are comparable to human infants at $36-38$ weeks of gestational age. 5,7 The $2-5$ days old piglets that are used for this experiment are therefore a good representative of late preterm to early term infants. We believe that the findings from our piglets could be translated to preterm infants who have very fragile cerebral vessels and are prone to develop IVH and/or periventricular leukomalacia.

The present study was designed to investigate whether (1) cerebrovascular dilation would persist during prolonged severe hypercapnia (2) cerebral vasculature function would remain intact during prolonged hypercapnia and, (3) addition of cerebral vasodilator or vasoconstrictor during hypercapnia may exaggerate cerebral vasodilation or vasoconstriction, respectively.

\section{METHODS}

All experiments involving animals were reviewed and approved by the University of Tennessee Health Science Center, Animal Care and Use Committee.

\section{SUBJECTS}

Experiments were performed on 2-5 days old newborn piglets of either sex, with weight ranging from 2 to $3 \mathrm{~kg}(n=10)$. Piglets were anesthetized with a mixture of ketamine hydrochloride (33 $\mathrm{mg} / \mathrm{kg}, \mathrm{IM})$ and xylazine $(3.3 \mathrm{mg} / \mathrm{kg}, \mathrm{IM})$ and maintained on

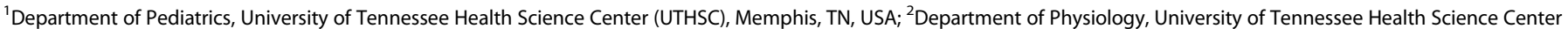
(UTHSC), Memphis, TN, USA and ${ }^{3}$ Department of Obstetrics/Gynecology, University of Tennessee Health Science Center (UTHSC), Memphis, TN, USA

Correspondence: Massroor Pourcyrous (mpourcyr@uthsc.edu)

Received: 22 December 2017 Revised: 16 April 2018 Accepted: 17 April 2018

Published online: 28 May 2018 
a-chloralose ( $30 \mathrm{mg} / \mathrm{kg}$ IV initially, followed by $3 \mathrm{mg} / \mathrm{kg}$ every $3 \mathrm{~h}$ ). Femoral artery and vein were cannulated to monitor BP, to withdraw blood samples for blood gases and $\mathrm{pH}$ analysis, and to administer anesthetics and fluids. The trachea was cannulated and intubated; piglets were ventilated mechanically with compressed air using a newborn positive pressure ventilator (Bourne's BP-200). Body temperature was maintained between 37.0 and $38.0^{\circ} \mathrm{C}$ with a servo-controlled heating pad; this is a normal rectal temperature in our piglets during the first week of life. Arterial $\mathrm{BP}, \mathrm{pH}$, and gases were monitored throughout the experiments. Arterial blood gases were measured periodically using Blood Gas Analyzer (Instrumentation Laboratory, Lexington, MA).

\section{CRANIAL WINDOW}

A closed cranial window was implanted over the left parietal cortex of each piglet for measurements of PADs, and for topical application of vasodilator and vasoconstrictor stimuli on cerebral cortex. To implant a closed cranial window, the head was immobilized and the scalp over the left parietal cortex was cut and retracted. A hole, $2 \mathrm{~cm}$ in diameter was made in the skull, and the dura was retracted. A stainless steel ring with a pre-mounted glass pane was inserted in the hole and sealed with bone wax. The window was cemented in place with dental acrylic, and the space under the window $(500 \mu \mathrm{l})$ was filled with artificial cerebrospinal fluid (aCSF) composed of (mM) $3.0 \mathrm{KCl}, 1.5 \mathrm{MgCl}_{2}, 1.5 \mathrm{CaCl}_{2}, 132$ $\mathrm{NaCl}, 6.6$ urea, 3.7 dextrose, and $24.6 \mathrm{NaHCO}_{3}$; with approximate $\mathrm{pH}$ of $7.33, \mathrm{PCO}_{2}$ of $45 \mathrm{~mm} \mathrm{Hg}$, and $\mathrm{PO}_{2}$ of $42 \mathrm{~mm} \mathrm{Hg}$. The ring has 3 ports, which allow injecting aCSF, vasodilators and vasoconstrictors directly under the cranial window and on the cortical surface. Pial arterioles were observed with a dissecting microscope, a television camera mounted on the microscope, and a video monitor. A video micrometer was used to measure the pial arteriolar diameters.

\section{DRUGS}

Three vasodilators (sodium nitroprusside (SNP), isoproterenol and glutamate) and two vasoconstrictors (endothelin and U46619) were used to evaluate cerebrovascular function. Sodium nitroprusside $\left(10^{-6} \mathrm{M}\right)$ and isoproterenol $\left(10^{-6} \mathrm{M}\right)$ are smooth muscledependent vasodilators, which act via cGMP and CAMP, respectively. Glutamate $\left(10^{-4} \mathrm{M}\right)$ is endothelium- and astrocytedependent vasodilator. Endothelin-1 was used at a concentration of $10^{-8} \mathrm{M}$, which induces vasoconstriction. U46619 $\left(10^{-6} \mathrm{M}\right)$ is a thromboxane A2 (TP) receptor agonist. All drugs and other compounds were purchased from Sigma Chemical Company (St. Louis, MO).

\section{PROTOCOL}

Cerebrovascular responses to vasodilators were evaluated in six piglets and to vasoconstrictors in four piglets. The experiment in each piglet was performed in two phases; normocapnia phase, followed by a hypercapnia phase. This allowed each piglet to act as its own control. After confirming that the BP and body temperature were within normal range, ventilator adjustment were made so that the blood gases were in normal range (pH 7.35-7.45, $\mathrm{PaCO}_{2} 35-45 \mathrm{~mm}$ of $\left.\mathrm{Hg}, \mathrm{PaO}_{2} 75-85 \mathrm{~mm} \mathrm{Hg}\right) . \mathrm{A}$ small pial arteriole $(40-60 \mu \mathrm{m})$ and a larger pial arteriole (80-100 $\mu \mathrm{m})$ were identified in each piglet and baseline diameters were measured. The same vessels were used for the entire duration of the experiment in each piglet.

During the normocapnia phase (first phase), each vasodilator or vasoconstrictor was separately infused under the cranial window that remained there for $5 \mathrm{~min}$, and maximum PAD responses were documented. At the end of $5 \mathrm{~min}$ and prior to the next challenge, the space under the cranial window was flushed gently and repeatedly with aCSF in order to allow the return of PADs to the baseline level that usually takes 10-15 min.

The hypercapnia phase (second phase) was started following the return of PAD to the baseline diameters. For hypercapnia, a gas mixture containing $10 \% \mathrm{CO}_{2}, 20 \% \mathrm{O}_{2}$ with balance nitrogen was introduced through the ventilator circuit to obtain and maintain $\mathrm{PaCO}_{2}$ between 75 and $80 \mathrm{~mm} \mathrm{Hg}$ for $120 \mathrm{~min}$. Pial arterioles that were dilated in response to hypercapnia were considered as the new baseline PAD. During hypercapnia similar to the normocapnia phase, each vasodilator or vasoconstrictor was separately infused under the cranial window that remained there for $5 \mathrm{~min}$. Maximum PAD response was recorded with each vasoactive stimulus at 30,60 , and 120 min of hypercapnia.

\section{DATA ANALYSIS}

Values are reported as mean \pm SEM. Comparisons among different time periods were made using analysis of variance with repeated measures and followed by Fisher's protected least significant difference test. The maximum cerebrovascular responses to various vasodilator and vasoconstrictor stimuli during normocapnia and hypercapnia were calculated as percent changes from the baseline-normocapnia. Comparisons were made using a paired $t$-test. A $P$ value $<0.05$ was considered significant.

\section{RESULTS}

Baseline $\mathrm{pH}, \mathrm{PaCO}_{2}, \mathrm{PaO}_{2}$, and arterial $\mathrm{BP}$ were within normal range during normocapnia. During hypercapnia, $\mathrm{PaCO}_{2}$ increased from $39 \pm 1.5$ to $76 \pm 0.7 \mathrm{~mm} \mathrm{Hg}$; consequently, $\mathrm{pH}$ decreased from $7.43 \pm 0.02$ to $7.19 \pm 0.01$ (Fig. 1). Piglets remained in room air and did not require any oxygen support. MABP was stable during experiment; piglets did not require any volume expansion or vasopressors. Pial arteriolar dilation was observed within a minute of hypercapnia, and dilation remained constant during $120 \mathrm{~min}$ of hypercapnia (Fig. 1).

During normocapnia, topical application of vasodilators (SNP, Fig. 2a; isoproterenol, Fig. 2b; glutamate, Fig. 2c) on cerebral cortex caused dilation of pial arterioles. Similarly, pial arteriolar dilatory responses to vasodilators were observed during hypercapnia. During hypercapnia, cerebral vessels were capable of further dilation when exposed to additional cerebral vasodilators (approximate increase in PAD from 20\% to 45\%). Topical application of endothelin-1 (Fig. 3a) and U46619 (Fig. 3b) caused constriction of pial arterioles during normocapnia as well as hypercapnia. However, vasoconstrictor responses were more pronounced during hypercapnia when compared with the normocapnia period $(p<0.05)$.

\section{DISCUSSION}

The new findings of present study include: (1) cerebrovascular dilation induced by an acute and severe hypercapnia was sustained during 120 min of experiment, (2) during hypercapnia, cerebrovascular reactivity to vasodilators and vasoconstrictors were preserved, suggesting, cerebrovascular function remained intact, (3) addition of second vasodilator during hypercapnia resulted in further dilation of pial arterioles and, (4) responses to vasoconstrictors during hypercapnia were two-fold higher during hypercapnia compared to normocapnia. These important findings suggest that, under hypercapnia state, CBF can still be manipulated by additional vasodilators and by vasoconstrictors.

Clinical relevance of the study

For this experiment, we chose $\mathrm{PaCO}_{2}$ of $75-80 \mathrm{~mm} \mathrm{Hg}$ and also we limited the duration of hypercapnia to $120 \mathrm{~min}$, with the aim of mimicking the clinical condition of unintentional and prolonged severe hypercapnia with respiratory acidosis. This condition can 
a

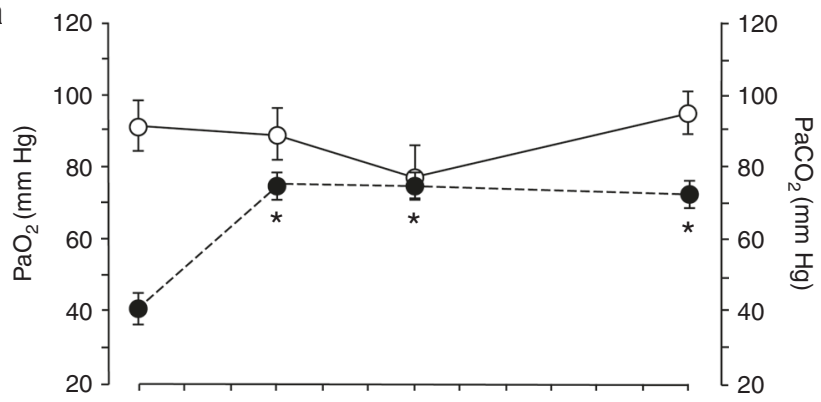

b

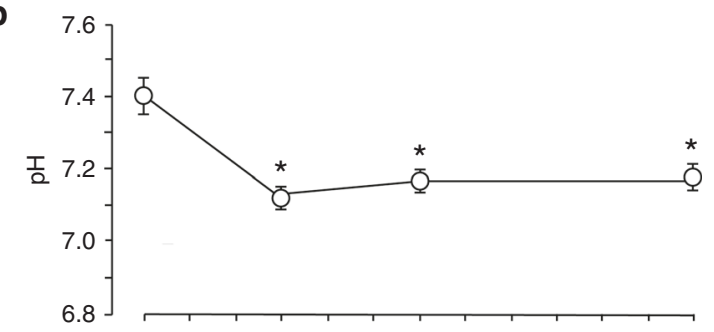

C

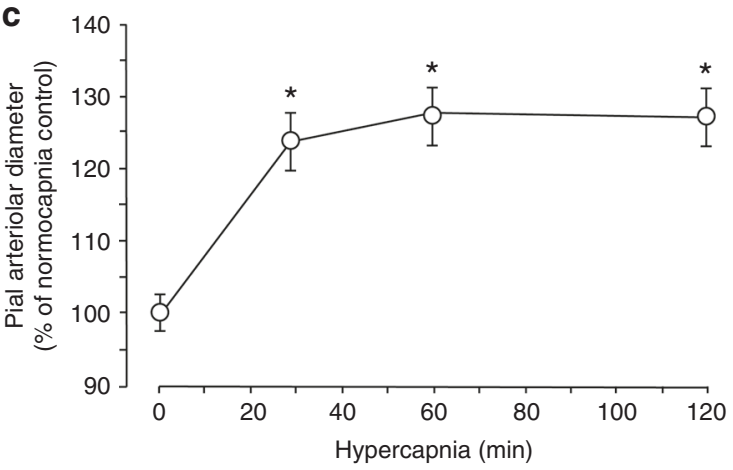

Fig. 1 Vasodilator responses of pial arterioles during prolonged hypercapnia. Changes in arterial blood $\mathrm{PaCO}_{2}$ and $\mathrm{PaO}_{2}$ (a), arterial blood $\mathrm{pH}(\mathbf{b})$, and pial arteriolar diameters (c) were monitored during normocapnia (0 min) and at 30,60, and $120 \mathrm{~min}$ of hypercapnia. Open circle represents $\mathrm{PaO}_{2}$ and closed circle represents $\mathrm{PaCO}_{2}$. $* P<0.05$ compared to normocapnia. $N=10$ piglets. Values are mean \pm SEM

occur in neonates experiencing respiratory illness, and is corrected when it is recognized. Our study was not intended to represent preterm infants with chronic pulmonary disease that due to the nature of their lung injury/disease, have chronic hypercapnia accompanied by compensatory metabolic alkalosis; the status of cerebrovascular function in these infants is unknown. Also, our study was not intended to mimic "permissive hypercapnia", which describes the practice of intentionally accepting higher $\mathrm{PaCO}_{2}$ level $(>45 \mathrm{~mm} \mathrm{Hg}$ ) in newborns that are mechanically ventilated, in order to minimize the ventilator-associated lung injury and therefore to decrease the short-term and long-term pulmonary morbidity. ${ }^{8}$ However, our findings may be relevant to the "permissive hypercapnia" strategy, since inadvertent severe hypercapnia may also occur in this group. Although, our piglet model is more representative of neonates at 36-38 weeks gestational age, we may extrapolate the findings to early preterm infants that have very fragile cerebral vasculatures and also have very narrow $\mathrm{CO}_{2}-\mathrm{CBF}$ autoregulatory zone. ${ }^{1}$

The effects of $\mathrm{PaCO}_{2}$ on PAD: a surrogate representative of CBF $\mathrm{PaCO}_{2}$ has major influence on cerebral circulation, with hypocapnia causing decreased CBF and hypo-perfusion, and hypercapnia causing increased CBF and cerebral hyper-perfusion. The blood brain-barrier allows gases, such as $\mathrm{CO}_{2}$, to diffuse from cerebral
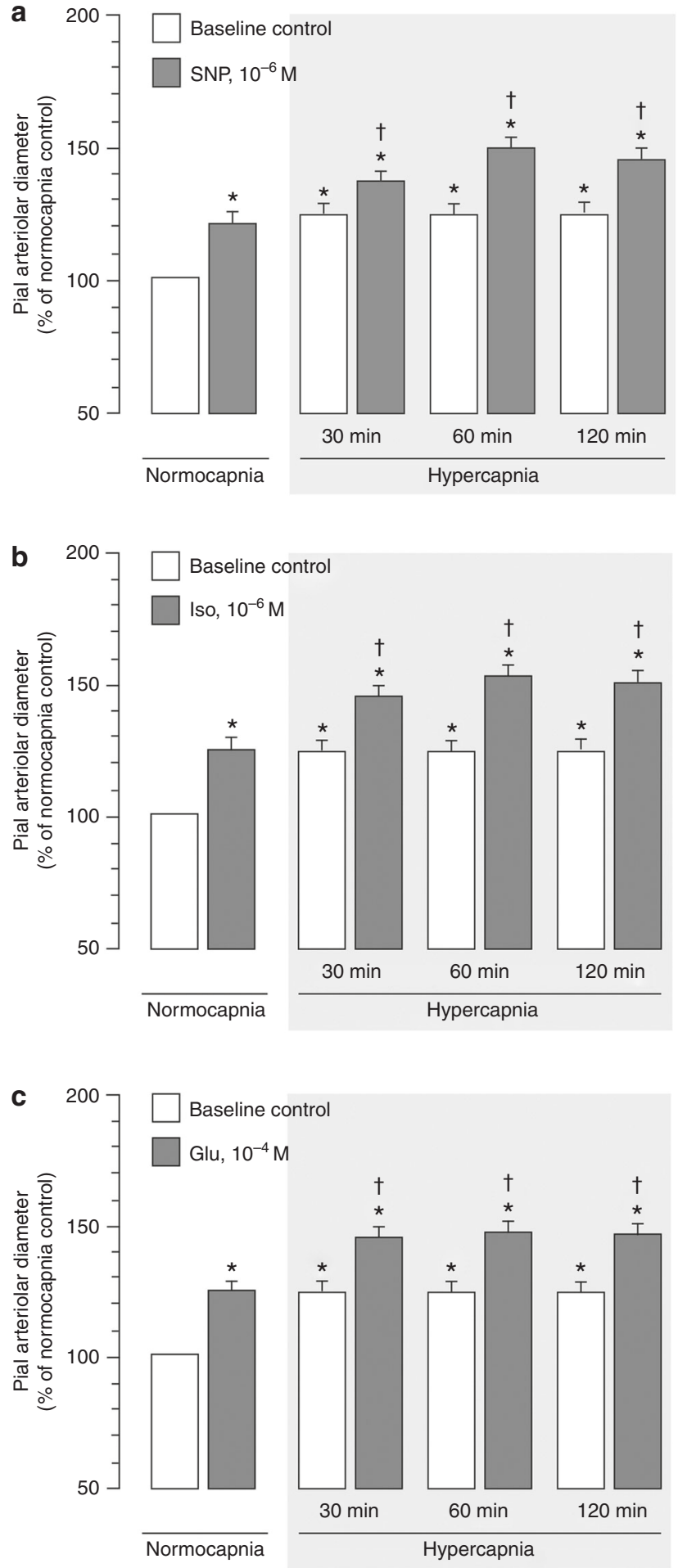

Fig. 2 a Vasodilator responses of pial arterioles to sodium nitroprusside (SNP, $\left.10^{-6} \mathrm{M}\right)$, (b) to isoproterenol (Iso, $10^{-6} \mathrm{M}$ ), and c to glutamate (Glu, $10^{-6} \mathrm{M}$ ). These agents were topically applied during normocapnia and prolonged hypercapnia $(30,60$, and 120 min). The arteriolar diameters are expressed as the \% of the normocapnia baseline control level. ${ }^{*} P<0.05$ compared with the normocapnia baseline. ${ }^{\dagger} P<0.05$ compared with the corresponding baseline control values. $N=6$ piglets; $N=12$ arterioles. Values are mean \pm SEM 

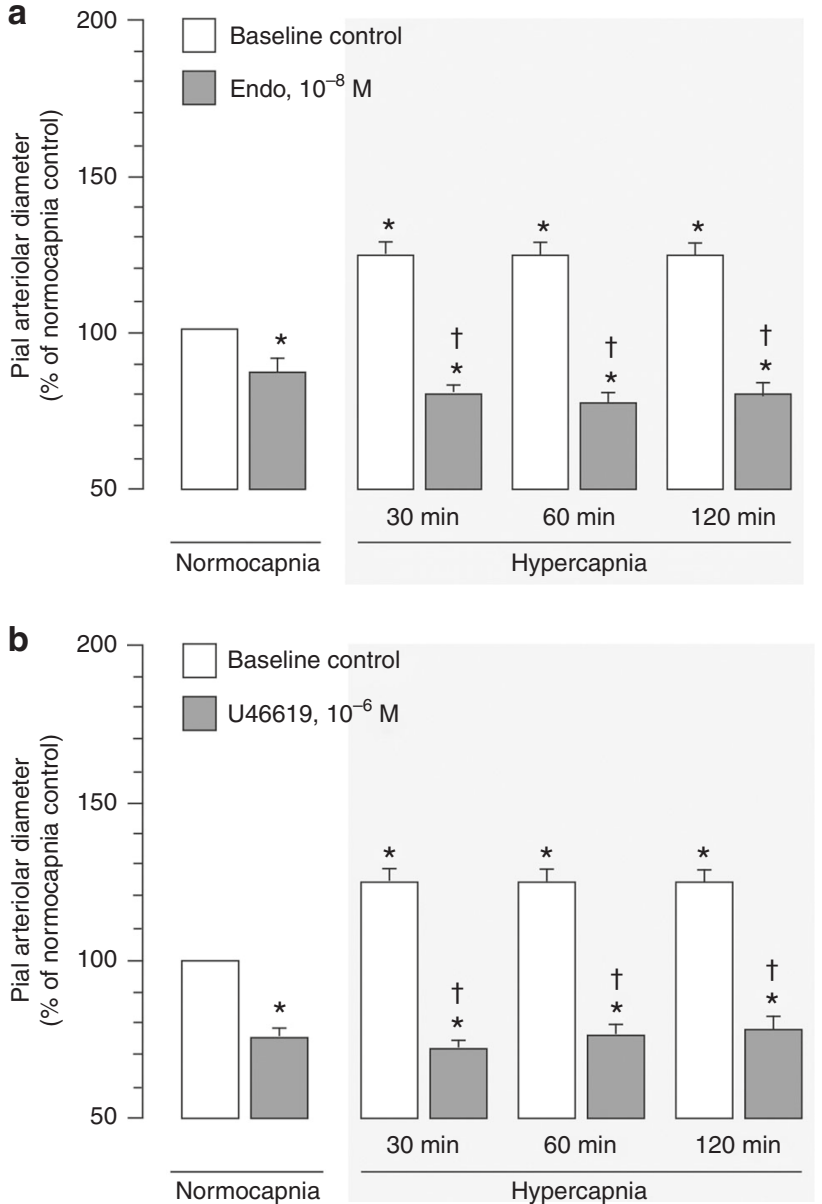

Fig. 3 a Vasoconstrictor responses of pial arterioles to endothelin-1 (Endo, $10^{-8} \mathrm{M}$ ) and to (b) U46619 $\left(10^{-6} \mathrm{M}\right)$. These agents were topically applied during normocapnia and prolonged hypercapnia $(30,60$, and $120 \mathrm{~min})$. The arteriolar diameters are expressed as the $\%$ of the normocapnia baseline control level. ${ }^{*} P<0.05$ compared with the normocapnia baseline. ${ }^{\dagger} P<0.05$ compared with the corresponding baseline control values. $N=4$ piglets; $N=8$ arterioles. Values are mean \pm SEM

vessels into the brain. Carbon dioxide affects the cerebral blood microvessels by changing the perivascular extracellular fluid $\mathrm{pH}$ and eventually equilibrating with the cerebrospinal fluid (CSF). Kontos et al. ${ }^{9}$ reported that alterations in the $\mathrm{pH}$ of CSF perfusing the pial arterioles have direct effect on pial arteriolar diameters; with acidosis dilating and alkalosis constricting the vessels. Blood flow is regulated by vascular resistance. Vascular resistance is determined to a lesser degree to the vessel length $(\mathrm{L})$ and blood viscosity $(\mu)$ but is inversely proportional to the radius of the vessels to the fourth power (Poiseuille's equation: $R=\mu \mathrm{L} / \mathrm{r}^{4}$ ). In the brain, pial arterioles are called the resistant vessels, ${ }^{1}$ and $\mathrm{PaCO}_{2}$ is an important factor that influences the pial arteriolar resistance. Therefore, changes in PAD could be considered as surrogate representative of changes in $\mathrm{CBF}$, granted the cerebrovascular function remains intact. However, damaged pial arterioles would not be a good representative of $\mathrm{CBF}^{10}$. Although, pial arterioles contribute to $<5 \%$ of total cerebral blood volume, minor changes in PAD would have major effects on CBF. ${ }^{11}$

The effects of $\mathrm{PaCO}_{2}$ on $\mathrm{CBF}$

Kety and Schmidt ${ }^{12}$ were the first to show that in adult human, acute changes in $\mathrm{PaCO}_{2}$ have profound effects on $\mathrm{CBF}(1 \mathrm{~mm} \mathrm{Hg}$ increase in $\mathrm{PaCO}_{2}$ resulted in $30 \%$ increase in $\mathrm{CBF}$ ). Later, a study on preterm infants indicated a $3-4 \%$ rise in $C B F$ per $1 \mathrm{~mm} \mathrm{Hg}$ increase in $\mathrm{PaCO}_{2} \cdot{ }^{13}$ In piglets that were exposed to hypercapnia $\left(\mathrm{CO}_{2} \geq 70 \mathrm{~mm} \mathrm{Hg}\right), \mathrm{CBF}$ increased by $2-5$ fold in different regions of the brain. However, the percent increase in CBF was the same in the cerebrum and the gray matter. ${ }^{14}$ Experiments in 3-5 d old rat pups demonstrated $\mathrm{CBF}-\mathrm{CO}_{2}$ reactivity at $13 \%$ per $1 \mathrm{~mm} \mathrm{Hg}$ $\mathrm{PaCO}_{2}{ }^{11}$ Grubb et al. ${ }^{15}$ reported in rhesus monkeys that $\mathrm{PaCO}_{2}$ increased CBF by 1 to $2 \mathrm{ml}$ per $100 \mathrm{~g}$ of brain tissue per min per 1 $\mathrm{mm} \mathrm{Hg}$ in $\mathrm{PaCO}_{2}$ rise. Similarly, Bell et al. ${ }^{16}$ reported blood flow changes of $1 \mathrm{ml}$ per $100 \mathrm{~g} / \mathrm{min}$ for each $1 \mathrm{~mm} \mathrm{Hg}$ change in $\mathrm{PaCO}_{2}$ in rats. Most recently, Pollock et al. ${ }^{17}$ using arterial spin-labeled MR perfusion imaging in patients with wide age differences (1.5-85 y old), showed cerebral perfusion changes by $4.0 \mathrm{ml}$ per $100 \mathrm{~g} / \mathrm{min}$ for each $1 \mathrm{~mm} \mathrm{Hg}$ change in $\mathrm{PaCO}_{2}$. Regardless of differences in the methodologies, age and the species, all above studies observed an increased CBF that ranged from 1 to $4 \mathrm{ml}$ per $100 \mathrm{~g}$ brain tissue/min for each $1 \mathrm{~mm} \mathrm{Hg}$ rise in $\mathrm{PaCO}_{2}$.

Prolonged hypercapnia and CBF adaptation

There is limited information on the effects of prolonged hypercapnia on $\mathrm{CBF}$, how long the vessels remain dilated during hypercapnia, and whether the vessels would recover after returning to normocapnic state. It is assumed that under prolonged steady-state hypercapnia, a time-dependent reduction of CBF towards baseline values occurs because of normalization of the CSF pH due to increased CSF bicarbonate levels. ${ }^{18,19}$ Acute changes in the extravascular $\mathrm{pH}$ secondary to high $\mathrm{PaCO}_{2}$ is counteracted by buffering processes in both intracellular and extracellular $\mathrm{pH}$ that leads to normalization of the arteriolar diameter. ${ }^{20}$ Brubakk et al. ${ }^{21}$ reported that maintaining hypercapnia at $60-70 \mathrm{~mm} \mathrm{Hg}$ for $4 \mathrm{~h}$ in awake-newborn pigs caused 2.5fold rise in $\mathrm{CBF}$ when measured at $30 \mathrm{~min}$, with gradual return towards baseline at $4 \mathrm{~h}$. In healthy awake sheep, remaining in an environmental chamber with $\mathrm{PaCO}_{2}$ of $53 \mathrm{~mm} \mathrm{Hg}$ for $96 \mathrm{~h}$ caused peak $C B F$ at one hour, with gradual readjustment but still elevated $\mathrm{CBF}$ at $24 \mathrm{~h}$; however after returning to room air, CBF still remained elevated for three hours. ${ }^{22}$ Healthy newborn lambs seem to tolerate undergoing hypercapnia $(75-80 \mathrm{~mm} \mathrm{Hg})$ for $6 \mathrm{~h}$ with a return to normocapnia, as shown by the return to baseline CBF and cerebral metabolism. ${ }^{23}$ In our present study on sedated newborn pigs, we observed a rapid increase in PAD in response to severe hypercapnia that represents increased CBF with no adaptation during 120 min of hypercapnia.

In adults human, increased middle cerebral artery blood flow was observed in response to $20 \mathrm{~min}$ of hypercapnia with a time to peak of $45 \mathrm{~s}$ without any adaptation in CBF. ${ }^{24}$ Also, in adults that remained in high ambient $\mathrm{CO}_{2}$ for 23 days, CBF velocity (CBFv) increased by $35 \%$ during first $1-3$ day of exposure to high $\mathrm{CO}_{2}$, after which CBFv progressively readjusted to pre-exposure levels. ${ }^{25}$ In children with airway obstruction or congenital hypoventilation syndrome, neurologic depression that was observed after prolonged hypercapnia $\left(\mathrm{PaCO}_{2}>150 \mathrm{~mm} \mathrm{Hg}\right.$ for $35 \mathrm{~min}$ to two days) with compensated metabolic alkalosis was reversible within $24 \mathrm{~h}$ of restoring normal $\mathrm{PaCO}_{2}{ }^{26}$ Currently, there is no information on preterm or term infants regarding to the adaptation of CBF during acute or chronic hypercapnia. As presented above, it is obvious that cerebrovascular adaptation to hypercapnia does occur. However, the degree of CBF adaptation may vary based on the methodology used, the severity and the duration of hypercapnia, awake or sedated condition, species, sex, age, and inter-individual variability.

\section{Permissive hypercapnia}

The idea of tolerating higher $\mathrm{PaCO}_{2}$ in preterm infants in order to decrease lung damage was first brought up by Avery et al. in 1987. ${ }^{27}$ Later, Hickling et al. ${ }^{28}$ reported that in adults with severe respiratory distress syndrome, permissive hypercapnia (mean maximum $\mathrm{PaCO}_{2}$ of $62 \mathrm{~mm} \mathrm{Hg}$ with the highest $\mathrm{PaCO}_{2}$ being $128 \mathrm{~mm} \mathrm{Hg}$ ) was associated with lower mortality rate. Gradually, 
the practice of "permissive hypercapnia' was adopted by pediatric intensivists and neonatologists. However, at times $\mathrm{CO}_{2}$ values might unintentionally exceed the planned $\mathrm{PaCO}_{2}$ range for "permissive hypercapnia" strategy. The first prospective randomized controlled trial of permissive hypercapnia $\left(\mathrm{PaCO}_{2} 45-55\right.$ $\mathrm{mm} \mathrm{Hg}$ ) was initiated by Mariani et al. ${ }^{29}$ in preterm infants who required mechanical ventilation. In that study, and also several other studies for "permissive hypercapnia" in neonates, although the duration of mechanical ventilation was reduced due to accepting a higher $\mathrm{PaCO}_{2}$ level, there were no differences between the normocapnia and hypercapnia groups for the incidence of air leaks, bronchopulmonary dysplasia, morbidity or mortality related to the lung injury. $8,29,30$ Those studies also reported as a secondary outcome the effects of "permissive hypercapnia" on the incidence of IVH but with a mixed report. The reason for the inconsistencies in the incidence of IVH includes: (1) not having an established optimum $\mathrm{PaCO}_{2}$ range, therefore $\mathrm{PaCO}_{2}$ level, as low as 45 and as high as $75 \mathrm{~mm} \mathrm{Hg}$ were considered as "permissive hypercapnia"; (2) the assigned $\mathrm{PaCO}_{2}$ ranges overlapped in the control and the hypercapnia groups; (3) "permissive hypercapnia" was practiced prior to the initiation of mechanical ventilation, during mechanical ventilation or both; and (4) the duration of "permissive hypercapnia" were different and ranged from 4 to10 days.

\section{Severe hypercapnia: brain pathology}

Many studies have shown that severe hypercapnia have undesirable effects on brain. Cystic infarcts was noted in hypoxic/ischemic immature rat pups subjected to severe hypercapnia $(99 \mathrm{~mm} \mathrm{Hg})$ compared to those who were normocapnic or subjected to mild hypercapnia $\left(\mathrm{PaCO}_{2} 54 \mathrm{~mm} \mathrm{Hg}\right){ }^{31,32}$ Increased cortical neuronal nuclei apoptosis was described in hypercapnic $\left(\mathrm{PaCO}_{2}>65 \mathrm{~mm} \mathrm{Hg}\right)$ newborn pigs. ${ }^{33}$ Das et al. $^{34}$ demonstrated increased TUNELpositive cells in developing brain of neonatal mouse pups exposed to chronic hypercapnia ( 6 days exposed to $8 \% \mathrm{CO}_{2}$ ).

Vasogenic exposure during hypercapnia and the effects on CBF There is physiologic limit to the hypercapnia-induced cerebrovascular dilation. Studies on rats, rhesus monkeys and on newborn piglets have shown that $\mathrm{PaCO}_{2}$ level of $80 \mathrm{~mm} \mathrm{Hg}$ seems to be the upper limits of maximum hypercapnia-induced cerebral vasodilation. ${ }^{35-37}$ Therefore CBF reaches a plateau level and increasing $\mathrm{PaCO}_{2}$ beyond this level may not further increase the CBF. However, we found that, when maximally dilated cerebral vessels induced by hypercapnia were exposed to another vasodilator, further cerebrovascular dilation occurred. Extrapolating our findings from piglets that are representative of late preterm infants to preterm infant is concerning, since preterm infants who are hypercapnic may also be exposed to medications and routine clinical interventions that may raise the CBF further. A significant increase in CBF may result in devastating cerebral injury in hypercapnic preterm, including rupture of fragile cerebral microvessels causing $\mathrm{IVH}$; damage the endothelium causing microhemorrhage, thrombosis and ischemic infarcts; or over-distension of cerebral vessels causing leaky vessels and brain edema. ${ }^{3,4,29}$

When we exposed the maximally dilated cerebral vessels induced by hypercapnia to a vasoconstrictor, it caused a pronounced pial arteriolar vasoconstriction. The findings of significant cerebral vasoconstriction that can be translated to decreased CBF is also concerning in infants regardless of their gestational age. Thus fluctuation of CBF during hypercapnia can occur as a result of hyper-perfusion and hypo-perfusion caused by exposure to vasodilators and vasoconstrictors, respectively.

\section{Limitations and strengths of our study}

Further studies are needed to find out whether the pial arterioles would respond in a similar manner if we had chosen a much higher $\mathrm{PaCO}_{2}(>100 \mathrm{~mm} \mathrm{Hg}$ ) level, or hypercapnia were continued for a longer period, or piglets were exposed to intermittent brief episodes of severe hypercapnia. Also, since our 2-5 d old piglets represent human infants at 36-38 weeks gestational age, studies on more immature piglets are needed as representative of extreme preterm infants who are prone to develop intraventricular hemorrhage due to CBF fluctuation.

\section{CONCLUSIONS}

Prolonged severe hypercapnia causes immediate and sustained vasodilation of pial arterioles indicative of hyper-perfusion. During 120 min period of hypercapnia, cerebral vascular responses to vasodilators and vasoconstrictors was preserved, indicating that cerebral vascular function remained intact and likely no cerebral vascular injury occurred. These data are the first to indicate that cerebral vessels during hypercapnia are capable of further dilation when exposed to additional cerebral vasodilators and, significant vasoconstriction when exposed to vasoconstrictors. Extrapolating these findings to human neonates, we suggest that severe hypercapnia should be avoided, since it may endanger them to potential risk of cerebrovascular injury specifically when they are super-exposed to vasodilators or vasoconstrictors.

\section{ACKNOWLEDGEMENTS}

We thank Alex L. Fedinec for technical assistance and Amanda Preston, PhD for the editorial assistance. This study was supported by National Institutes of Health, Bethesda, MD RO1NS101717 (H.P.), RO1HL034059 and RO1HL42851 (C.W.L.).

\section{ADDITIONAL INFORMATION}

Competing interests: The authors declare no competing interests.

Publisher's note: Springer Nature remains neutral with regard to jurisdictional claims in published maps and institutional affiliations.

\section{REFERENCES}

1. Greisen, G. Autoregulation of cerebral blood flow in newborn babies. Early Hum. Dev. 81, 423-428 (2005)

2. Kaiser, J. R., Gauss, C. H. \& Williams, D. K. The effects of hypercapnia on cerebral autoregulation in ventilated very low birth weight infants. Pediatr. Res. 58, 931-935 (2005)

3. Kaiser, J. R., Gauss, C. H., Pont, M. M. \& Williams, D. K. Hypercapnia during the three days of life is associated with severe intraventricular hemorrhage in very low birth weight infants. J. Perinatol. 265, 279-285 (2006).

4. Fabres, J., Carlo, W., Phillips, V., Howard, G. \& Ambalavanan, N. Both extremes of $\mathrm{PaCO}_{2}$ and the magnitude of fluctuations are associated with severe intraventricular hemorrhage in preterm infants. Pediatrics 2, 299-305 (2007).

5. Dobbing $\mathrm{j}$ and Sands, J. Comparative aspects of the brain growth spurt. Early Hum. Dev. 311, 79-83 (1979).

6. Buckley, N. M., Gootman, P. M., Yellin, E. L. \& Brazeau, P. Age-related cardiovascular effects of catecholamines in anesthetized piglets. Circ. Res. 45, 288-292 (1979).

7. Pon, W. G. \& Haupt, K. A. The Biology of the Pig. (Cornell University Press, Ithaca, 1978) 99.

8. Thome, U. H. et al. Permissive hypercapnia in extremely low birthweight infants (PHELBI): a randomized controlled multicenter trial. Lancet Respir. Med. 3, 534-543 (2015).

9. Kontos, H. R., Raper, A. J. \& Patterson, J. L. Analysis of vasoreactivity of local pH, $\mathrm{PCO}_{2}$ and bicarbonate on pial vessels'. Stroke 8, 358-394 (1977).

10. Pourcyrous, M., Parfenova, H., Bada, H. S., Korones, S. B. \& Leffler, C. W. Changes in cerebral cyclic nucleotides and cerebral blood flow during prolonged asphyxia and recovery in newborn pigs. Pediatr. Res. 41, 617-623 (1997).

11. Pryds, A., Tonnesen, J., Pryds, O., Knudsen, G. M. \& Greisen, G. Cerebral pressure auto regulation and vasoreactivity in the newborn rat. Pediatr. Res. 57, 294-298 (2005).

12. Kety, S. S. \& Schmidt, C. F. The effects of altered arterial tensions of carbon dioxide and oxygen on cerebral blood flow and cerebral oxygen consumption of normal young men. J. Clin. Invest. 27, 484-492 (1948).

13. Pryds, O. \& Greisen, G. Effect of $\mathrm{PaCO}_{2}$ and Hemoglobin concentration on day to day variation of CBF in preterm neonates. Acta Pediatr. Scand. Suppl. 360, 33-36 (1989). 
14. Pourcyrous, M. et al. Cerebrovascular responses to therapeutic dose of indomethacin in newborn pigs. Pediatr. Res. 45(4 Pt 1), 582-587 (1999).

15. Grubb, R. L.Jr, Raichle, M. E., Eichling, J. O. \& Ter-Pogossian, M. M. The effects of changes in $\mathrm{PaCO}_{2}$ on cerebral blood volume, blood flow, and vascular mean transit time. Stroke 5, 630-639 (1974).

16. Bell, B. A., Foubister, G. C., Neto, N. G. \& Miller, J. D. Effect of experimental common carotid arteriotomy on cerebral blood flow in rats. Neurosurgery 16, 322-326 (1985).

17. Pollock, J. M. et al. Hypercapnia-induced cerebral hyperperfusion: an underrecognized clinical entity. Am. J. Neuroradiol. 30, 378-385 (2009).

18. Warner, D. S., Turner, D. M. \& Kassell, N. F. Time-dependent effects of prolonged hypercapnia on cerebrovascular parameters in dogs: acid-base chemistry. Stroke 18, 142-149 (1987)

19. Levasseur, J. E., Wei, E. P., Kontos, H. A. \& Patterson, J. L. Jr. Responses of pia arterioles after prolonged hypercapnia and hypoxia in the awake rabbit. J. Appl. Physiol. 46, 89-95 (1979).

20. Lassen, N. A. Brain extracellular pH: The main factor controlling cerebral blood flow. Scand. J. Clin. Lab. Invest. 22, 247-251 (1968).

21. Brubakk, A. M., OH, W. \& Stonestreet, B. S. Prolonged hypercapnia in the awake newborn piglet: effect on brain blood flow and cardiac output. Pediatr. Res. 21, 29-33 (1987).

22. Yang, S. P. \& Krasney, J. A. Cerebral blood flow and metabolic responses to sustained hypercapnia in awake sheep. J. Cereb. Blood Flow. Metab. 15, 115-123 (1995).

23. Hino, J. K., Short, B. L., Rains-Bahrami, K. \& Seale, W. R. Cerebral blood flow and metabolism during and after prolonged hypercapnia in newborn lambs. Crit. Care Med. 28, 3505-3510 (2000). 385

24. Poulin, M. I., Liang, P. I. \& Robbins, P. A. Dynamics of the cerebral blood flow response to step changes in end-tidal $\mathrm{PCO}_{2}$ and $\mathrm{PO}_{2}$ in humans. J. Appl. Physiol. 81, 1084-1095 (1996).

25. Sliwke, U., Krasney, J. A., Simon, S. G., Schmidth, P. \& Noth, J. Effects of sustained low-level elevations of carbon dioxide on cerebral blood flow and auto regulation of the intracerebral arteries in humans. Aviat. Space Environ. Med. 69, 299-306 (1998).

26. Goldstein, B., Shannon, D. C. \& Todres, I. D. Supercarbia in children: clinical course and outcome. Crit. Care Med. 18, 166-168 (1990).

27. Avery, M. E. et al. Is chronic lung disease in low birth weight infants preventable? a survey of eight centers. Pediatrics 79, 26-30 (1987).

28. Hicking, K. G., Henderson, S. J. \& Jackson, R. Low mortality associated with low volume pressure limited ventilation with permissive hypercapnia in severe adult respiratory distress syndrome. Intensive Care Med. 16, 372-377 (1990).

29. Mariani, G., Cifuentes, J. \& Carlo, W. A. Randomized trial of permissive hypercapnia in preterm infants. Pediatrics 104(5 pt 1), 1082-1088 (1999).

30. Ambalavanan, $\mathrm{N}$. et al. $\mathrm{PaCO}_{2}$ in surfactant, positive pressure, and oxygenation randomized trial (SUPPORT). Arch. Dis. Child. Fetal Neonatal Ed. 100, F145-F149 (2015)

31. Vannucci, R. C., Towfighi, J., Brucklacher, R. M. \& Vannucci, S. J. Effect of extreme hypercapnia on hypoxic-ischemic brain damage in the immature rat. Pediatr. Res. 49, 799-803 (2001).

32. Vannucci, R. C., Towfighi, J., Heltjan, D. F. \& Brucklacher, R. M. Carbon dioxide protects the perinatal brain from hypoxic-ischemic damage: an experimental study in immature rats. Pediatrics 95, 868-874 (1995).

33. Fritz, K. I., Zubrow, A., Mishra, O. P. \& Delivoria-Papadopoulos, M. Hypercapniainduced modifications of neuronal function in cerebral cortex of newborn piglets. Pediatr. Res. 57, 299-304 (2005)

34. Das, S., Du, Z., Bassly, S., Singer, L. \& Vicencio, A. G. Effects of chronic hypercapnia in the neonatal mouse lung and brain. Pediatr. Pumonol. 44, 176-182 (2009).

35. ladecola, C. \& Zhang, F. Nitric oxide-dependent and independent components of cerebrovasodilation elicited by hypercapnia. Am. J. Physiol. 266, R546-R552 (1994).

36. Reivich, M. E. Arterial $\mathrm{PCO}_{2}$ and cerebral hemodynamics. Am. J. Physiol. 206, 25-35 (1964).

37. Parfenova, H., Shibata, M., Zuckerman, S. \& Leffler, C. W. $\mathrm{CO}_{2}$ and cerebral circulation in newborn pigs: cyclic nucleotides and prostanoids in vascular regulation. Am. J. Physiol. 266, H1494-H1501 (1994). 